\title{
Applied-Information Technology for the Strength of Intellectual Property Protection Based on Digital Transmission
}

\author{
Xiuhu Tan \\ Journalism Department, Chengdu Sport University, Chengdu, China \\ txhchinese@163.com
}

\begin{abstract}
The development of society depends on the success of innovation activities, and intellectual property rights are becoming increasingly important for the development of human society. In this paper, based on the analysis of the status and existed problem of sport digital intellectual property, we present a dynamic framework for the research of the interactions between sport intellectual property and competition, and understand the impact of such policies on future incentives. In order to analyze the problems of legal regulation and protection of sport intellectual property and reveal the main factors that influence upon the system of sport intellectual property rights protection, we present suggestions for improving sport intellectual property regulation, so as to play a pushing role both in the theory and the practice of sport intellectual property.

Keywords: Intellectual Property, Transmission, Protection

\section{Introduction}

Among the different engines of economic growth, none has received as much attention as innovation. From the economic point of view, the asset can be divided into tangible asset and intangible asset, and the knowledge economy is built on the production, configuration and application of knowledge and information and exists mainly with intangible asset investment [1]. Intellectual property is a dynamic concept, and the development of technology makes the content and scope of intellectual property protection constantly change [2].With the development of the age and the process of technology, sports competition has grown from the original simple physical competition to the competition of economy, technology and management and other aspects, to promote modern sports toward specialization and technicalization, so as to generate a lot of sports intellectual property in the field of sports [3].
\end{abstract}

\section{Definition of Sports Intellectual Property}


Sports digital intellectual property is the digital manifestation of sports intellectual property, and not only has the characteristics of general sports intellectual property, but also has its own unique dissemination characteristics. In the digital environment, the dissemination of sports intellectual property has the following aspects of characteristics.

\section{Diversified route of dissemination.}

In the traditional mode of dissemination, the obligee is always based on certain actual material carrier to transfer sports intellectual property [4]. And the transfer of sports intellectual property generally requires the participation of a certain amount of intermediary organizations, and the number of routes of dissemination is limited [5-6]. However, in the digital environment, all dissemination information are digitized into symbols, and the dissemination of sports intellectual property may not need the actual material carrier, nor need the participation of intermediary organizations, and the obligee and receiver can directly transfer sports intellectual property through a network, and the route of dissemination is diversified.

\section{Open mode of dissemination.}

The traditional dissemination way of sports intellectual property requires handwriting, printing and replication, and the participation of intermediaries and limited routes of dissemination, and the obligee can control the dissemination of sports intellectual property. But in the digital communication age, anyone can make use of digital technology to copy, download and edit sports intellectual property, and needs neither special equipment nor a lot of time, and can operate and complete with high quality on general computer terminal.

\section{Free copy and dissemination.}

In the traditional means of communication, the copy and dissemination of sports intellectual property need to take a fee. However, in the digital environment, digital technology can change copy content into digitally encoded information without actual material carrier, and the copy and dissemination of digital information are completed instantaneously, and the users do not need any cost to obtain the reproductions of sports intellectual property.

\section{Multimedia feature of dissemination.}

Traditional communication way of sports intellectual property is generally through the paper printed material, television and radio individual carrier. But in the digital age, technological advances make sports intellectual property spread on different carriers, such as video, audio, Flash animation, images and texts, and the obligee can choose some type for communication and also can fuse different types of sports knowledge property information to spread. 


\section{Influence of Digital Dissemination on the Protection of Sports Intellectual Property}

\section{Protection issues on sports intellectual property brought by digital dissemination}

Popularization and application of computers and networks has made digital information become the primary way for people to access information. By means of the computer network, people can conveniently release and exchange digital information and products though the Internet, and can copy and transmit digital information and products with almost no loss. However, the consequent negative impacts often occur, for example, certain individuals or groups can privately carry out a large number of illegal copying and dissemination of works through the network without the copyright owner's permission in the case of not been authorized or approved, and judicial disputes arising from copyright infringement and content tampering increase rapidly (Fig 1).

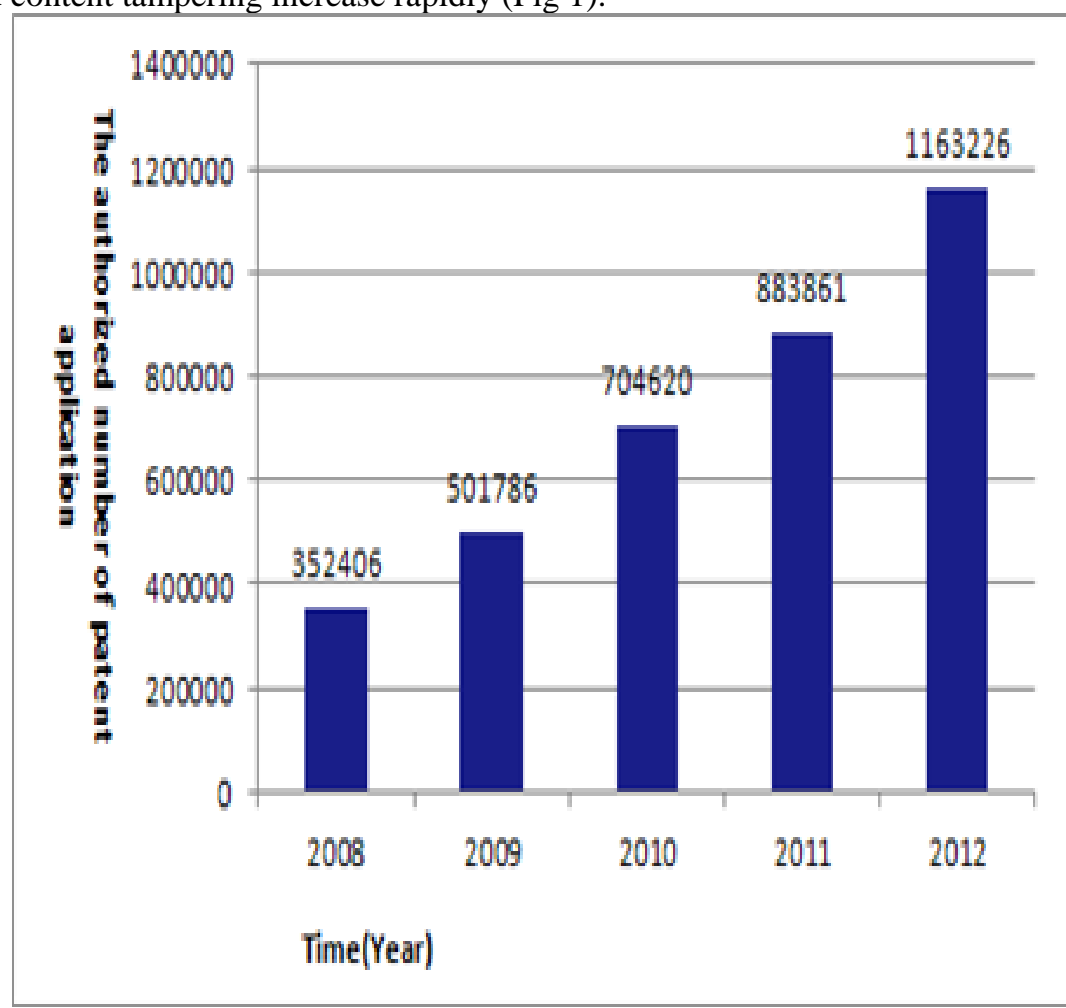

Fig 1 The Authorized Number of Patent Application

Occurrence reasons for the infringement of digital dissemination of sports intellectual property 
Basic laws and regulations of the protection of sports intellectual property exist deficiencies.

In recent years, China has increased efforts to protect sports intellectual property. "People's Republic of China Sports Law” Article 35 issued in August 1995 provides the legal basis for the protection of sports logos, but only to provide protection for sports logos of major sports events. The protection of sports intellectual property should not be only limited to sports logos, and developed countries in Europe and America have begun to protect sports intellectual property of sports performance.

\section{Protection awareness of sports digital intellectual property is not strong.}

Sports intellectual property protection plays a leading role in the sports industry restructuring. In the traditional planned economy pattern, because of public welfare of sports, the public do not regard sports with commercial nature, and a lot of people in the sports circle also have the thought of "valuing results and underestimating patents", that is, paying more emphasis on the protection of tangible sports intellectual property with weak protection awareness of invisible sports intellectual property, thus resulting in a lot of China's sports intellectual property "registered in advance" annually. For example, after China's successful bidding for Olympics, many relevant sites’ domain names have been registered, seriously affecting the market development and brand promotion activities of Beijing Organizing Committee of Olympic Games.

\section{Protection staff of sports digital intellectual property is deficient}

Sports intellectual property protection involves cultural, legal and political fields and many aspects, but the majority of China's sports institutions and enterprises have few talents to master the related knowledge of intellectual property, and basically do not have full-time staff positions for intellectual property work and do not establish intellectual property management department. When sports intellectual property disputes occur, on the one hand, the infringer is quite familiar with the computer and network technology, with high-tech means of infringement of sports intellectual property; on the other hand, sports institutions and enterprises need to collect the evidences in order to safeguard the legal rights, which needs investigators to have a considerable understanding of information technology.

\section{Related research on sports digital intellectual property protection is not in-depth enough.}

The current domestic research on sports intellectual property is still in a very weak stage, related research results is very limited, the protection of sports intellectual property lacks theoretical research, and the research content is mainly related to the status of intellectual property protection, institution building and coping strategies, lacking the performance evaluation and analysis of digital 
dissemination copyright protection system of sports intellectual property at the present stage, lacking the research of regularity of digital dissemination of sports information and lacking qualitative and quantitative analysis based on actual data. The protection of sports digital intellectual property will not only strengthen the construction and improvement of relevant laws and regulations, but also combine specific rules of sports digital dissemination, and research the protection of sports digital intellectual property and technological means and methods of information security from the perspective of communication technology.

\section{Digital technology brings new security risks for sports intellectual property} protection.

In the traditional mode of dissemination, sports intellectual property is borne in material carrier, and it is easier to control the dissemination and storage of sports intellectual property. However, in the digital communication environment, sports intellectual property can be represented in binary symbols and can be stored in digital form. Digital information is simple to copy, easy to carry, easy to modify and easy to disseminate, making it difficult to control the dissemination and protect.

\section{Improvement of Sports Digital Intellectual Property Protection System and Methods}

\section{Strengthen the construction and improvement of basic rules and regulations of sports digital intellectual property protection}

Under the background of sports power, it is necessary to perfect sports intellectual property laws and regulations and strengthen the law enforcement efforts of sports intellectual property protection. In terms of sports intellectual property protection system, government and the subject of right and relative subject have a dynamic game, and the game process ultimately determines the system selection and institutional change of sports intellectual property protection system. Sports management departments at all levels should continue to accelerate the construction of the relevant laws, regulations and administrative agencies, designedly strengthen the professional training of relevant personnel, improve their professional quality as soon as possible, continuously improve the effectiveness and transparency of law enforcement in judicial practice, making laws to be abided by and ensured the observation, and making the legislation and law enforcement of China's sports intellectual property protection in line with international standards, so as to further enhance public confidence of sports intellectual property system in the world, to create a favorable institutional environment of sports intellectual property protection.

Strengthen and improve development strategy of sports digital intellectual property, and enhance independent innovation capability 
Develop sports intellectual property strategy and enhance the independent innovation capability. Sports management departments at all levels must examine the domestic sports independent innovation capacity from the national strategic height, because sports scientific and technological progress of a country and regions really needs to learn the digestion and absorption of foreign advanced technology, but ultimate catching-up of sports technology still must rely on the enhancement of their own independent innovation capacity, and only independent innovation capacity with the sports core technologies and key technologies can effectively digest and absorb the international advanced sports science and technology.

\section{Strengthen research and protection of sports digital intellectual property under new technology conditions}

Construct sports power and strengthen the protection research of sports digital intellectual property which is a new sports intellectual property under the new technical conditions. Protection of sports digital intellectual property not only needs to develop and innovate system regulations of sports intellectual property protection, but also needs to eliminate safety hazards of sports intellectual property value spread based on information security technology point of view. Sports digital intellectual property protection needs to be considered comprehensively from the technical level and system level.

\section{Strengthen the construction of monitoring and maintenance systems of sports digital intellectual property and the training of professionals}

In the information age, the use of traditional methods such as manual search of information gathering has been unable to effectively implement the monitoring and analysis of information, so professional and technical means must be taken advantage to achieve real-time monitoring, timely detection and statistical verification of Internet information. Meanwhile, aiming at different types of infringement ways of sports digital intellectual property, data collection and verification methods are also different, and the collected infringement information also needs to be screened, analyzed, calculated and tracked, which requires to establish the monitoring and maintenance systems of sports digital intellectual property.

\section{Conclusion}

China is facing a turning point from a sports country to a sports power, and the environment and requirements of sports digital intellectual property protection also change dramatically. Only the strengthening of intellectual property protection can promote the healthy and orderly development of sports cause, so as to achieve a win-win and even multi-win situation.

\section{References}


[1] Xiaohong. Q, Chesbrough, H: IEEE Trans, Engineering Management. Vol. 57(1) (2010), p. 9.

[2] Sheng. Wei, Nahapetian. Aand Potkonjak M: IEEE Trans, Information Forensics and Security. Vol. 8(11) (2013), p. 1722.

[3] Chip-Hong. C, Li. Z: IEEE Trans, Computer-Aided Design of Integrated Circuits and Systems. Vol. 33(1) (2014), p. 76.

[4] Saha. D, Sur-Kolay. S: IEEE Trans, Computers \& Digital Techniques. Vol. 4(5) (2010), p. 388.

[5] Maes. R, Schellekens. D: IEEE Trans, Information Forensics and Security. Vol. 7(1) (2012), p. 98.

[6] Xiong. S, Bogy: IEEE Trans, Magnetics. Vol. 50(3) (2014), p. 102. 